\title{
Discussion on Green Building Design and Humanistic Care
}

\author{
Shuhai $\mathrm{Wu}^{1}$, Qing Liu* \\ School of Civil Engineering, Qinghai University, 810016Qinghai, China
}

\begin{abstract}
Green building design is regarded as the key content of building design, which has been paid more and more attention in the development of the construction industry. Therefore, green building design is a new direction of architectural design development. Embodying humanistic care is the functional requirement of green building design in modern society. It's crucial to study the correct direction of green building design and humanistic care development for the future of construction industry.
\end{abstract}

\section{INTRODUCTION}

Nowadays, our society are facing a great challenge of environmental pollution, which means green building design is more significant. Green building design can create healthy, comfortable and safe environment for people, meanwhile, integrating humanistic care into green building design can improve people's comfort of the environment. This paper started with the term of "green building design" and analyse the key point of green building design to make clear the focal point of green building design with the idea of humanistic care integrated into it. Following the analysis, this paper discussed the application strategy of humanistic care in green building design. And in consideration of the actual situation, this paper proposed some solutions for the full integration of green building design and humanistic care and the creation of a better living and working environment for human beings.

\section{Summary of green building design}

Green building design is a people-oriented design concept, which is scientific and reasonable. The green building design has a natural concept for the design of ventilation systems such as daylighting and integrated greening, and realizes the green and humanized design inside and outside the building. Humanistic care is integrated into the design of green buildings, aiming at achieving harmony between people, architecture and nature and providing people with a simple and comfortable life. At the same time, it has played a big role in the stability of the community and the maintenance of the environmental ecosystem. Green building design has become an inevitable trend in the development of modern social construction industry.

\section{Analysis of the design emphasis of green building design}

\subsection{Ensure the health of the occupants}

People are the most fundamental service target of green building design. Because of its people-oriented principle, it is necessary to pay attention to the protection of people's health in green design. In the practical operating process of green building design, it is necessary to use building materials that meet the national quality standards to reduce the damage of building materials to the human body. Air Quality, humidity and radiation must be up to standard, considering the health of the occupants. No participant of a construction project can build an architecture only out of mercenary motives. And it's unacceptable to cut material costs in order to reduce construction costs and cut corners using nonconforming materials. Only by truly ensuring the health index of the material, can we pay more attention to health protection while creating a comfortable environment.

\subsection{Water recycling}

Water shortages are a problem that the whole world is facing. This problem cannot be solved fundamentally even today. Therefore, in daily life, water conservation and the design of water recycling is very important. In the practical operating process of green building design, A water system that facilitates the recycling of water resources is vital, which not only can be used once in water, but also can be used multiple times. In this way, the architectural design will be more in line with the standards and principles of green building design.

It is clear that green building design is a system design technology, so to ensure the realization of water conservation, the water supply and drainage design should be integrated into the system design technology. The concept of water saving and water resources recycling should be reflected in the design of water supply and drainage in all aspects of green building design. Only by adopting proper water-saving

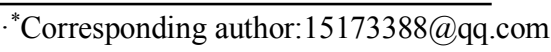


technology such as using water-saving sanitary ware and reasonable water pressure control measures can we meet the expected water saving targets.

\subsection{Full use of natural resources}

In addition to the use of renewable energy in green building design, making full use of natural energy is also required, that is, the use of natural light and wind by lighting and ventilation systems. Natural light and wind energy is inexhaustible, and more environmentally friendly, compared with the use of electric appliances, such as electric lamps and air conditioners. Green building design using sunlight can not only bring appropriate brightness, but also sterilization. The use of sunlight in green buildings design not only provides suitable brightness, but also sterilizes. The use of natural ventilation and lighting system can also achieve the goal of green energy conservation while improving the building environment comfort. ${ }^{[1]}$

Natural resources should be fully utilized in green building design, which can reduce the consumption of secondary energy during the use of the building and optimize the architectural design. This requires designers to analyse the wind direction, sunshine regularity and temperature conditions of the construction before the layout of the building to clarify the direction of the building design, and then make full use of natural lighting, rainwater circulation and renewable energy such as waste heat. Taking the Shanghai Natural History Museum as an example, the building fully implements the concepts and methods of green building design. First of all, through the use of technologies such as greening and heat insulation exterior walls and energy-saving curtain walls, the building will transform the building external envelope structure that directly affects the overall insulation and heat consumption of the building into energy-conserving facility. In the next place, the rainwater recycling system is used to treat and reuse the rainwater collected in the central pool and roof. The building also uses skylight lighting to solve the problem of electricity and hot water supply by using solar power technology.

\subsection{More rationalized building structure}

The structure is the soul of the building. If the structure is not well grasped, the performance and function of the building cannot be improved most effectively. On the contrary, in the practical operating process of green building design, with a more rationalized building structure, a basic platform for the rational allocation and use of resources can be provided. Therefore, in the architectural structure design, more rationalized building structure should be made, in order to be more in line with the humanities idea and provide occupants with a green, healthy and comfortable environment.

\section{Design Requirements of green building under humanistic care}

\subsection{Spatial rationalization}

In the design of the space, the rational planning and combination of the space must be focus on. Different from the building structure, the rational design of the space can bring the most intuitive feeling to the occupants. In addition to the rational design of ventilation and illumination, the proportion of houses and toilets should be appropriate. Appropriate use of mirrors and other similar materials can visually expand the space of the house, making the space design of the house more reasonable, and bring the most comfortable feeling to the occupants. ${ }^{[2]}$

\subsection{Greening design of buildings}

When designing green buildings, humanistic care should be taken into consideration, and indoor and outdoor green design should be emphasized. Greening is the way to satisfy the contact between human and nature. Proper greening area can make residents feel that they are in nature even though living in the city. In addition, the photosynthesis of green plants can produce oxygen, bringing a more liveable air environment for residents. And the photosynthesis of green plants produces oxygen, which brings more habitable air conditions to occupants. At the same time, green plants can block the sun, lower the temperature, lock the water, and make the living environment more comfortable and environmentally friendly. ${ }^{[3]}$

In addition to greening the ground around the building, it's also necessary to make full use of the external walls, roofs, balconies for greening expansion. For example, planting climbing plants on the exterior walls of buildings can be used to beautify the external walls of buildings while absorbing harmful gases and purifying the air. And roof greening can regulate temperature and reduce noise. By combining landscape greening and three-dimensional greening, the green building design can not only solve the ecological and environmental problems, but also maximize the psychological needs of people connecting with nature.

\subsection{Integration with local residential environment}

Green building design is based on the values of harmonious symbiosis between architecture and environment. Integrating humanistic care into green building design means that the building not only has to coexist harmoniously with the natural environment, but also coordinate with the human settlement environment.

China has a vast territory and a long history. The climate and culture of each region are very different. The buildings we are currently using are the essence of the wisdom of our people for thousands of years. For example, the difference between the south and the north of China is very large. Due to the high temperature and heavy rain in the south, most of the houses in the south have sloping roofs, which can help the south to contribute to drainage and pipeline transportation during 
the rainy season. In the north, due to the lack of drought and precipitation, most of them are flat-top houses which are good for rainwater storage and warm in winter. This is not only the difference between methods of construction and the appearance. These living environments have penetrated the hearts of local residents and shaped the local residents' perceptions and emotions about the original areas. ${ }^{[4]}$

This requires green building design to combine the green lifestyle of the new era with the traditional local social life model. In other words, while traditional cultural elements are being expressed, it is necessary to cultivate a green lifestyle that aims towards the future. Specifically, when constructing a separate green building project, the original residential quarters and settlements should be respected, and the integration and overall effect with the surrounding local buildings should be considered to create a unique and unobtrusive residential environment.

\section{Application Strategy of Humanistic Care in Green Building Design}

\subsection{Combination of Chinese and Western Architectural Style}

The concept of green architecture design is being widespread. In pursuit of high-quality green building design, there is obvious limitation in developing only one kind of architectural concept. Creating the best green building design requires combination of the concepts and methods of green building design in China and the West, which means conceptual plans and detailed architectural design schemes in the West should be used for reference.

\subsection{Personalized design}

The more information modern people are exposed to, the greater the difference between people's ideas and requirements. In the modern era of information, architectural design needs to be tailored to people, and different green architectural designs are made according to different ideas and requirements. ${ }^{[5]}$

To achieve the personalization of green building design is to combine the concept of energy conservation, return to nature, and environmental friendliness with the requirements of residents' living and use. Guided by the needs of the occupants, the building space should be carefully designed and refined through simulations of the living conditions of the occupants. The fundamental goal of green building design should be "life" itself, so it should not be just a technical science of energy or construction engineering but a focus on individualized aspects of life.

\subsection{Environmental protection}

Green building design should pay attention to reducing damage to the natural environment and environmental pollution. The disposal method of construction waste, sewage, gas, and domestic garbage should be designed. In order to minimize the environmental burden, it is necessary to restrict the use of building materials that have a large impact on the environment, select renewable materials and clean energy, and recycle old materials. Only in this way can the building achieve the green design concept and be responsible for the health of the occupants, and truly achieve the organic combination of green design and human care.

The environmental protection property and ecology of green building design considerably depends on the choice of green materials. The selection of building materials should follow the principle of adapting to local conditions and materials can be recycled, because the scientific and rational use of building materials in green building design not only involves environmental protection issues, but also directly relates to human health and building safety issues. Nowadays, China's building materials industry is still in the stage of high resource consumption, high pollution, low efficiency and extensive production. There are problems such as air pollution, building materials waste and wastewater pollution, radioactive material pollution and organic volatiles. Therefore, we should pay attention to the selection of green building materials: 1. Select as much as possible the recycling type building materials that use construction materials in large quantities. 2. Select energy-saving building materials obtained through lowenergy, non-polluting production processes. 3. Use healthy building materials that do not use harmful chemicals such as formaldehyde, halide solvents or aromatic hydrocarbons. ${ }^{[6]}$

\subsection{Application of BIM technology}

Parameterizing the application of human care in green building design can greatly improve their integration efficiency, and BIM technology is the most effective way to achieve this. BIM is short for Building Information Modelling, to put it simply, it is a technology that uses the information data of construction engineering as a basis to build a building model and uses the model to perform data simulation to achieve technical analysis. ${ }^{[7]}$ It can optimize the allocation of resources, parameterize the concepts of Spatial rationalization and Greening design of buildings, and set up corresponding simulation and information model analysis such as daylight tracking simulation, as shown in the figure:

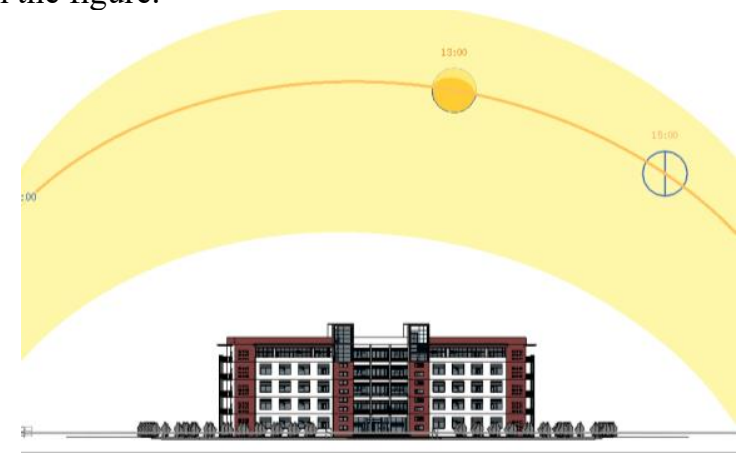

Fig. 1. Daylight tracking simulation by BIM software 
When designing a green building, it is necessary to effectively determine the sustainability of the building environment and the efficiency of energy use. However, in the face of some complex and general engineering project simulation analysis and analysis work, only the traditional engineering examples and parameter calculation methods often result in low precision, slow speed and large error. BIM technology can be used to integrate the building function system, maintenance system and equipment system, comprehensively consider the structure, space and function modules of the building, optimize the allocation of building resources, and achieve the environmental protection and green energysaving design goals of the building. For example, BIM technology can execute collision analysis to make sure the rationality of water supply and drainage plan while achieving the goal of water saving, as shown in the figure:

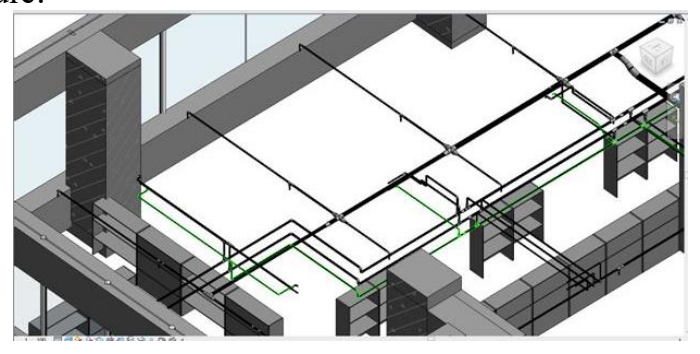

Fig. 2. Water supply and drainage plan by BIM software

In the planning and design stage, BIM technology can carry out data simulation analysis on various majors such as architecture, structure, and plumbing, so that the analysis of green building evaluation indicators such as sunshine and natural ventilation can be changed from qualitative to quantitative. And in the construction phase, the fine management of building materials through BIM technology can minimize energy and material consumption.

\section{Conclusion}

Green building design is the development trend of future buildings, and humanistic Care is also an inevitable requirement for future development. Integrating green building design into humanistic care is an important embodiment of the significance of sustainable development. Cleverly integrating the design ideas of humanistic care into green building design, grasping the key points and requirements of green building design is an important way to promote the development of China's construction industry, and also an important embodiment of China's sustainable development.

\section{References}

1. RJ. Li, Residential and Real Estate 3, 66 (2016)

2. K. Huang, South Architecture, 6, 70-75 (2014)

3. W. Yue, Modern Decoration (Theory), 10, 81(2011)

4. QB. Liu, JF. Tian, Optimization of capital construction, 5, 91-94(2005)
5. T. Li, X. Fu, Housing Industry, 10, 17-21 (2015)

6. YF. Zhang, Green Environmental Protection Building Materials, 6, 1-2(2019)

7. JD. Ma, House, 20, 66(2019) 